\title{
Development of an LC-MS/MS Method for the Assessment of Selected Active Pharmaceuticals and Metabolites in Wastewaters of a Swiss University Hospital
}

\author{
Silwan Daouk ${ }^{\star a c}$, Sandrine Fleury-Souverain ${ }^{\mathrm{a}}$, and Youssef Daali ${ }^{\mathrm{b}}$
}

\begin{abstract}
A multi-residue analytical method was developed and validated for the quantification of 11 selected active pharmaceutical ingredients (API) and 2 human metabolites in hospital effluents using solid-phase extraction followed by liquid chromatography coupled to tandem mass spectrometry (LC-MS/MS). Targeted analytes belong to different therapeutic classes: non steroidal anti-inflammatory drugs (NSAID), analgesics, antibiotics and psychiatric drugs. Solid-phase extraction recoveries ranged between 21 and $101 \%$ for the selected API. Calibration curves were built with 6 standard samples prepared in ultrapure water ranging from 0.05 to $10 \mu \mathrm{g} / \mathrm{L}$ and showed regression coefficients above 0.994. The instrumental detection limits (IDL) varied between 0.05 and $5 \mu \mathrm{g} / \mathrm{L}$, and the method detection limits (MDL) between 0.1 and $100 \mathrm{ng} / \mathrm{L}$. Precision of the method, evaluated with spiked water samples at four different concentrations, varied between 84 and $117 \%$ for all compounds and an overall variability below 20\%, with the exception of carbamazepine (71-123\%). Except for two compounds, recoveries of spiked hospital wastewaters at four different concentrations $(0.1$, 1,10 and $100 \mu \mathrm{g} / \mathrm{L}$ ) varied between 44 and $133 \%$, with relative standard deviation (RSD) between 0.6 and $28.5 \%$. The evaluation of the matrix effects showed that diluted samples exhibit lower signal suppression. Analysis of effluent samples from a Swiss university hospital resulted in a mean detection frequency of $92 \%$ for the selected compounds, with concentrations up to $1535 \mu \mathrm{g} / \mathrm{L}$ for the analgesic paracetamol.
\end{abstract}

Keywords: Hospital wastewaters · Liquid chromatography $\cdot$ Mass spectrometry $\cdot$ Pharmaceuticals

\section{Introduction}

Active pharmaceutical ingredients (API) are known to be released into the aquatic environment by different sources, but urban wastewater treatment plants (WWTP) are considered to be the main contributors. ${ }^{[1]}$ A significant proportion of this point source pollution comes from hospitals and health care facilities, which are susceptible to the release of specific

'Correspondence: Dr. S. Daouk ${ }^{\mathrm{ac}}$

E-mail: Silwan.Daouk@unil.ch

aGeneva University Hospitals (HUG)

Pharmacy, Quality Control Laboratory

Gabrielle Perret-Gentil 4

$\mathrm{CH}-1211$ Geneva 14

${ }^{\circ}$ Geneva University Hospitals (HUG)

Clinical Pharmacology and Toxicology, Pharmacology

and Toxicology Laboratory

Gabrielle Perret-Gentil 4

$\mathrm{CH}-1211$ Geneva 14

'Current address: University of Lausanne

Institute of Earth Surface Dynamics, Géopolis

$\mathrm{CH}-1015$ Lausanne compounds. ${ }^{[2-4]}$ Hospitals contribute indeed to the pollution of the urban water network with a broad range of API, as well as diagnostic agents, heavy metals and antibiotic-resistance bacteria. ${ }^{[2,5,6]}$ Regarding API, the hospital contribution represents only $10-25 \%$ of the urban load found at the watershed outlet. ${ }^{[1,7,8]}$ Because most of the pharmaceutical compounds are not well degraded during WWTP treatments, they can represent a threat to aquatic species. ${ }^{[9,10]}$ The development of appropriate analytical tools for the quantification of API residues in hospital effluents represents a prerequisite for a better understanding of this environmental pollution.

During the last decade, developed analytical methods allow the simultaneous quantification of an increasing number of API with various properties in hospital and urban wastewaters at low concentrations (ng/L- $\mu \mathrm{g} / \mathrm{L}$ range). ${ }^{[11-13]}$ According to the objectives of the study and the targeted molecules, method protocols differ although they all contain a filtration and an extraction step due to the complexity of environmental matrices. Concerning multiresidue methods using liquid chromatography coupled to tandem mass spectrom- etry (LC-MS/MS), all authors are using a reversed phase (RP) column, allowing the separation of polar and hydrophobic molecules contained in the mobile phase. ${ }^{[12,14,15]}$ Most of the molecules are analyzed after a positive ionization, but a negative ionization is preferred for some molecules, mainly acidic ones such as NSAID (ketoprofen, diclofenac, ibuprofen, indomethacin, mefenamic acid), diuretic (furosemide), antilipemic agents (clofibric acid, bezafibrate, gemfibrozil, pravastatin), cytostatics (fluorouracil), etc. ${ }^{[12,14,16]}$

The present work is aimed at developing and validating an LC-MS/MS method for the quantification of selected API of different therapeutic classes and some of their associated human metabolites in hospital effluents. API selection was done according to previous prioritization work, ${ }^{[17]}$ but also to the antecedent detection in local surface waters, ${ }^{[18]}$ the analytical feasibility, and the probability to find residues in the sewer of the studied hospital. The API retained were the anti-inflammatories ibuprofen and diclofenac, the analgesics paracetamol, codeine and morphine, the antibiotics metronidazole, sulfamethoxazol, ciprofloxacin and piperacillin, the psy- 
chiatric drugs gabapentin and carbamazepine, and the metabolites metronidazolehydroxyl and mefenamic acid-hydroxyl.

\section{Material and Methods}

\subsection{Chemicals and Reagents}

Analytical and isotopically labeled standards were all of high purity grade (>98\%). Paracetamol (acetaminophen), metronidazole, codeine, morphine, sulfamethoxazol, ciprofloxacin, carbamazepine, metronidazole-hydroxyl, ibuprofen, piperacillin, diclofenac, mefenamic acidhydroxyl, paracetamol-d4, morphine-d3, gabapentin-d10 and ibuprofen-d3 were purchased from Sigma-Aldrich (Buchs, Switzerland), sulfamethoxazol-d4 from LGC standards (Wesel, Germany) and gabapentin from Toronto Research Chemicals (Ontario, Canada). HPLC-grade methanol $(\mathrm{MeOH})$ and acetonitrile $(\mathrm{ACN})$, as well as $\mathrm{HCl}$ and formic acid were purchased from Sigma-Aldrich (Buchs, Switzerland). Ultrapure water $(18.2 \mathrm{M} \Omega \times \mathrm{cm})$ was obtained using a Millipore system (Millipore Ltd., Bedford, USA).

\subsection{Standards Solutions}

Stock solutions of $500 \mathrm{mg} / \mathrm{L}$ of each standard were prepared in methanol and kept at $-20{ }^{\circ} \mathrm{C}$, except for ciprofloxacin which was prepared in water. A mixed working solution with the 13 compounds was prepared in methanol/water (50:50, $v / v)$, from which six calibration standards were obtained by spiking ultrapure water samples at concentrations ranging from 0.01 to $10 \mu \mathrm{g} / \mathrm{L}$ according to compound. A mixed solution of internal standards at a concentration of $2 \mathrm{mg} / \mathrm{L}$ was prepared in methanol and kept at $-18{ }^{\circ} \mathrm{C}$. Internal standards were added to standards and samples to reach a concentration of $10 \mu \mathrm{g} / \mathrm{L}$.

\subsection{Sample Preparation}

For the solid phase extraction (SPE), Strata-X polymeric reversed phase cartridges were used (Phenomenex, Torrance, CA, USA). In order to embrace the large discrepancies between API concentration levels in hospital wastewaters, samples were analyzed twice:

With a concentration factor of 50: $50 \mathrm{~mL}$ of hospital wastewater samples were filtered through a $1.6 \mu \mathrm{m}$ glass fiber filter followed by $0.45 \mu \mathrm{m}$ nylon filter. Samples were then diluted twice with $50 \mathrm{~mL}$ of ultrapure water acidified to $\mathrm{pH} 3$ using $1 \mathrm{M}$ $\mathrm{HCl}$, and $0.1 \mathrm{~mL}$ of internal standard solution was added. Samples were passed through Strata-X polymeric reversed phase cartridges ( $200 \mathrm{mg}, 6 \mathrm{~mL}$ ), previously conditioned with $5 \mathrm{~mL}$ of $\mathrm{MeOH}$ and $5 \mathrm{~mL}$ of ultrapure water acidified to $\mathrm{pH} 3$. They were then rinsed with $3 \mathrm{~mL}$ of acidified water and air dried for 20 minutes. Analytes were eluted with $4 \mathrm{~mL}$ of $\mathrm{MeOH}$ and evaporated to dryness using a vacuum system at $40{ }^{\circ} \mathrm{C}$ (Mivac SpeedTrap, Genevac) and retrieved in $1 \mathrm{~mL}$ of $0.1 \%$ of formic acid:acetonitrile (80:20, v/v).

With a dilution factor of 5: $0.2 \mathrm{~mL}$ of filtered wastewaters and $0.1 \mathrm{~mL}$ of internal standard solution were diluted in $1 \mathrm{~mL}$ of ultrapure water acidified to $\mathrm{pH} 3$ and passed through Strata-X polymeric reversed phase cartridges (60 mg, $3 \mathrm{~mL}$ ), previously conditioned with $3 \mathrm{~mL}$ of methanol and $3 \mathrm{~mL}$ of ultrapure water acidified to $\mathrm{pH} 3$. They were then rinsed with $3 \mathrm{~mL}$ of acidified water and air dried for 20 minutes. Analytes were eluted with $2 \mathrm{~mL}$ of $\mathrm{MeOH}$ and evaporated to dryness and retrieved in 1 $\mathrm{mL}$ of $0.1 \%$ of formic acid:acetonitrile $(80: 20, v / v)$.

\subsection{LC-MS/MS}

The LC system (Agilent 1100 Series) was equipped with a $\mathrm{C}_{18}$ column (Discovery $^{\circledR} 150 \times 2.1 \mathrm{~mm}$ i.d., particle size $5 \mu \mathrm{m}$, from Supelco), preceded by a guard column with the same stationary phase $(20 \times 2.1 \mathrm{~mm}$ i.d., particle size $5 \mu \mathrm{m})$. The elution of the compounds from the column was obtained using a mobile phase consisting of ultrapure water with $0.1 \%$ of formic acid (solvent A) and acetonitrile (solvent $\mathrm{B})$. The gradient elution was: $2 \% \mathrm{~B} 0-1$ min, 2-80\% B 1-4 min, 80\% B 4-5 min, 80-2\% B 5-5.5 min, 2\% B 5.5-11 min, with a total time of $11 \mathrm{~min}$. The flow rate and the injection volume were set at 0.5 $\mathrm{mL} \min ^{-1}$ and $10 \mu \mathrm{L}$, respectively.

The LC was coupled to a tandem mass spectrometer (API 4000, AB Sciex) with an electrospray ionization operated in both positive and negative mode according to compound. The multiple reaction monitoring (MRM) mode was used and two MRM transitions were monitored for proper quantification (MRM 1) and confirmation (MRM 2). Nitrogen was used as the curtain and nebulizer gas and the turbo spray conditions were as follows: curtain gas: $30 \mathrm{psi}$; collision gas: 8 psi; ion spray voltage: \pm 4.5 $\mathrm{kV}$; temperature: $600{ }^{\circ} \mathrm{C}$; ion source gas 1 : $30 \mathrm{psi}$; ion source gas 2: $40 \mathrm{psi}$.

\subsection{Method Performance Evaluation}

The response function of the method was tested in ultrapure water with six calibration standards ranging from 0.05 to 10 $\mu \mathrm{g} / \mathrm{L}$ according to compound, corresponding to 2.5 to $500 \mu \mathrm{g} / \mathrm{L}$ instrument range due to the SPE concentration. Each standard was injected twice at the beginning and at the end of the run and calibration curves were built using a linear regression model with a $1 / x$ weighting.

Quantitative performance of the developed method was evaluated in three sepa- rate series. The accuracy of the method was tested with four different Quality Control (QC) samples, ranging from 0.05 to $8 \mu \mathrm{g} / \mathrm{L}$ according to compound and prepared and analyzed in triplicate in ultrapure water. Trueness at each concentration level was expressed in percent and calculated as the mean of the ratios between measured values and nominal concentrations of the nine samples. Repeatability and intermediate precision were expressed as the intra-day (CVr) and inter-day (CVR) coefficients of variation, respectively, and calculated using ANOVA. Dilution integrity was assessed by calculating trueness, $\mathrm{CVr}$ and CVR of QC samples spiked at 100 and $1000 \mu \mathrm{g} / \mathrm{L}$, diluted five times and analyzed in triplicate.

The method performance was estimated in hospital wastewater by evaluating mean recoveries of triplicate samples spiked at four concentrations: 0.1, 1, 10 and $100 \mu \mathrm{g} / \mathrm{L}$. The last one was diluted five times to fall in the calibration range. Five samples of blank matrix were analyzed and subtracted to spiked samples.

The matrix effects were evaluated by calculating the signal suppression as the ratio between signal areas observed in spiked hospital wastewater samples (A matrix) and in the solvent (A solvent; $0.1 \%$ formic acid/acetonitrile, 80:20, $v / v)$, after appropriate subtraction of peak areas of analytes present in the samples (A blank):

Signal suppression $(\%)=100-[(\mathrm{A}$ matrix - A blank) $\times 100$ / A solvent]

The instrumental detection limits (IDL) and quantification limits (IQL) were determined as the minimum detectable amount of analyte with a signal-to-noise ratio of $3: 1$ and $10: 1$, respectively, by injection of decreasing concentrations of the standard mixture. The method detection limits (MDL) were defined as the IDL divided by the concentration factor (50), while the method quantification limits (MQL) as equal to the lowest standard.

\subsection{Application to Hospital Effluent Samples}

Hospital wastewater was sampled with a refrigerated automatic sampler (ISCO 6712, Avalanche) in the sewer of the main building of the Geneva University Hospitals (HUG). The sampling was done flow-proportional during two different weeks: May 28 - June 1 and July 15-18, 2014. The sewer pipe was equipped with a sharp-crested rectangular weir for the flow rate determination. An ultrasonic flow meter device (ISCO 4210) was installed upstream of this latter, and the wastewater height measurements was done every 2 min and checked for accuracy at least every 2 weeks. The flow rate was then cal- 
culated according to the Kindsvater-Carter equation (Eqn. (1)):[19]

$$
Q=3.33(L-0.2 H)\left(H^{3 / 2}\right)
$$

where $\mathrm{Q}=$ discharge $\left[\mathrm{m}^{3} / \mathrm{s}\right], \mathrm{L}=$ weir width $[\mathrm{m}], \mathrm{H}=$ height $[\mathrm{m}]$.

Daily loads were then estimated with a basic numeric integration (Eqn. (2)):[20]

$$
\text { Load }=k \sum c_{i} q_{i} t_{i}
$$

where $\mathrm{k}$ is a unit conversion factor, $\mathrm{c}_{\mathrm{i}}$ the concentration of the sample $i, q_{i}$ the discharge at its sampling time $\left(\mathrm{t}_{\mathrm{i}}\right)$, and $\mathrm{t}_{\mathrm{i}}=0.5$ $\left(\mathrm{t}_{\mathrm{i}+1}-\mathrm{t}_{\mathrm{i}-1}\right)$.

Each sample was taken after $20 \mathrm{~m}^{3}$ and eight samples were mixed in one bottle, resulting in composite samples representative of $160 \mathrm{~m}^{3}$. They were kept at $5{ }^{\circ} \mathrm{C}$ until analysis. In every sequence of analysis, blanks and quality control (QC) samples at $50 \mu \mathrm{g} / \mathrm{L}$ in the mobile phase were included in the middle of samples.

\section{Results and Discussion}

\subsection{Method Optimization}

\subsubsection{Solid-phase Extraction}

During solid-phase extraction (SPE), sample $\mathrm{pH}$ adjustment influences the extraction yields according to the compound and the sorbent phase. Indeed, an acidic $\mathrm{pH}$ of 2-3 is likely to increase the co-extraction of matrix compounds such as humic acids, which leads to more severe signal suppression during the LC-MS/MS analysis.[13,21] Strata-X polymeric reversed phase cartridges were previously shown to achieve better recoveries for many compounds at $\mathrm{pH}$ 3.[21] Due to the multiple interactions possible between API molecules and this sorbent phase ( $\pi-\pi$ stacking, H-bonding, and hydrophobic interactions) recovery likely depends on $\mathrm{pH}$ conditions and the acid dissociation constants (pKa) of the studied compounds. In our case, extraction recoveries ranged from 10.1 to $106.3 \%$ at pH 7 (mean: $74 \pm 13 \%$ ) and from 21.5 to $101.3 \%$ at $\mathrm{pH} 3$ (mean: $72 \pm 6 \%$ ) for the selected API (Fig. 1). For some compounds, higher yields were obtained at $\mathrm{pH} 7$, while for others better yields were achieved at $\mathrm{pH} 3$. Indeed, the analgesic morphine exhibits a strong decrease of its extraction recovery under acidic conditions, while the antiepileptic gabapentin and the antibiotic piperacillin showed improved yields. The antibiotic ciprofloxacin was not tested because it has been added to the method afterwards, due to its potential high risk for the aquatic ecosystems. ${ }^{[17]}$ The acidification of samples was chosen since a lower global variability and better recoveries for piperacillin and gabapentin were achieved.

\subsubsection{Liquid Chromatography}

Several aqueous (ammonium formate, ammonium acetate, $0.1 \%$ formic acid) and organic mobile phases (methanol, acetonitrile, $0.1 \%$ formic acid in $\mathrm{ACN}$ ) were tested in advance. For both the positive and the negative ionization mode, the best separation was obtained with ultrapure water with $0.1 \%$ of formic acid (solvent A) and acetonitrile (solvent B) (Fig. 2). Several elution gradients were tested in order to optimize the separation of compounds and the total run time, and the optimum elution gradient (see section 2.4) resulted in a total run time of $11 \mathrm{~min}$ in both positive and negative modes. The retention factor $(\mathrm{k})$ of the less retained compound (morphine) on the chromatographic column was checked to be greater than 2 . The morphine signal exhibited some noise before the main peak (Fig. 2), but its quantification was not affected when this latter was integrated the same way in the deuterated internal standard.

\subsubsection{Mass Spectrometry}

The detection in the triple quadrupole was operated in the multiple reaction monitoring (MRM) mode, and the optimum fragmentation conditions for each compound (declustering potential (DP), collision energy (CE) and collision cell exit potential (CXP)) were obtained by direct injection of $50 \mu \mathrm{g} / \mathrm{L}$ individual standard solution in $\mathrm{MeOH} / \mathrm{H}_{2} \mathrm{O}(50: 50, v / v)$
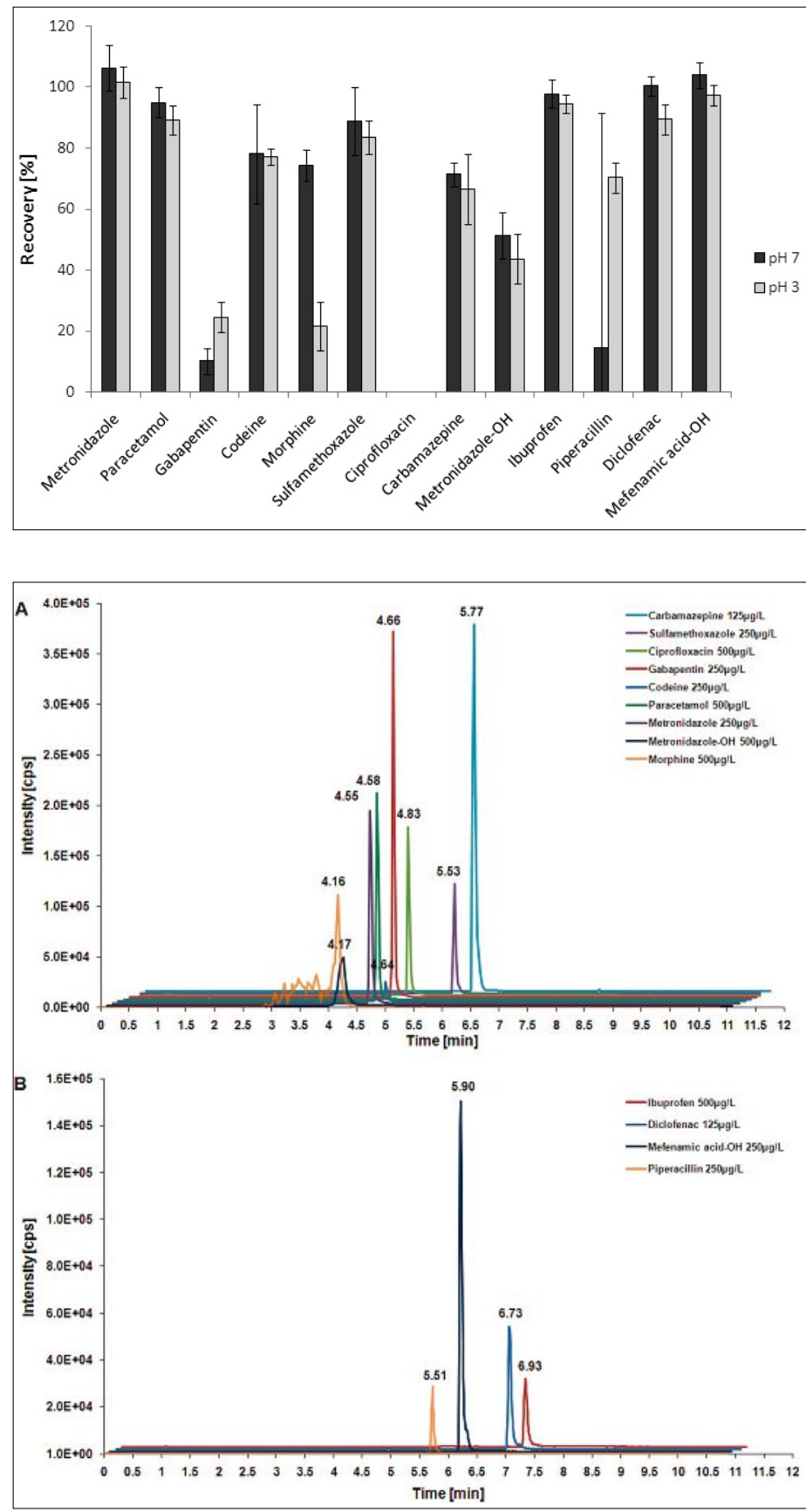

Fig. 1. Solid-phase extraction recoveries using Strata-X reverse phase cartridges at $\mathrm{pH} 7$ and 3 . Ciprofloxacin was not analyzed because it was added to the method afterwards as explained in the text.

Fig. 2. Chromatogram of the selected API analyzed in (A) positive and (B) negative ionization mode. For clarity a drift was applied to retention times, but they are indicated. 
at $0.6 \mathrm{~mL} / \mathrm{min}$ in full scan mode (Table 1). The two most abundant fragment ions were selected and compound quantification was done according to the first transition (MRM 1), while the second transition (MRM 2) was used for confirmation, with the exception of the NSAID diclofenac and the mefenamic acid metabolite (mefenamic-OH) which showed poor fragmentation. The fragmentation of the analgesics morphine and codeine showed the same product ion (MRM 1: 152), but the parent ion, the second fragment, and the collision energy were different allowing their differentiation. Quantification was performed using internal standard calibration with deuterated compounds to correct for sample preparation, extraction losses and potential matrix effects. Five IS were chosen and the correction of analytes was done with the closest IS in terms of retention time.

\subsection{Method Performance}

Calibration curves created using a $1 / \mathrm{x}$ weighting factor showed good response function within the chosen concentration ranges with regression coefficients above 0.995, except for carbamazepine for which it was 0.994 (Table 2). The calibration ranges $(2.5-500 \mu \mathrm{g} / \mathrm{L})$ were chosen based on expected concentrations for each substance in the hospital effluents. Due to the double preparation for each sample, the method concentration ranges vary from

Table 1. Mass spectrometry parameters for the analysis of selected compounds in positive (+) and negative (-) ionization mode (IS: Internal standard; DP: Declustering potential; MRM: Monitoring Reaction Mode; CE: Collision Energy; CXP: Collision Cell Exit Potential).

\begin{tabular}{|c|c|c|c|c|c|c|c|c|c|c|}
\hline Compound & IS & Polarity & Precursor Ion & DP & MRM 1 & $\mathrm{CE}$ & CXP & MRM 2 & $\mathrm{CE}$ & CXP \\
\hline Metronidazole & PAR-d4 & + & 172.1 & 41 & 128.1 & 19 & 6 & 82 & 33 & 4 \\
\hline Paracetamol (PAR) & PAR-d4 & + & 152.19 & 26 & 110.1 & 23 & 6 & 135.1 & 9 & 8 \\
\hline Gabapentin (GAB) & GAB-d10 & + & 172.14 & 46 & 154.1 & 17 & 10 & 137.1 & 23 & 8 \\
\hline Codeine & PAR-d4 & + & 300.18 & 66 & 152.1 & 85 & 8 & 115.1 & 95 & 6 \\
\hline Morphine (MOR) & MOR-d3 & + & 286.17 & 71 & 152.2 & 77 & 8 & 128.2 & 75 & 8 \\
\hline $\begin{array}{l}\text { Sulfamethoxazole } \\
\text { (SMX) }\end{array}$ & SMX-d4 & + & 254.09 & 56 & 156 & 21 & 8 & 108 & 33 & 4 \\
\hline Ciprofloxacin & SMX-d4 & + & 332.24 & 61 & 288.2 & 25 & 18 & 314.2 & 29 & 20 \\
\hline Carbamazepine & SMX-d4 & + & 237.17 & 61 & 194.2 & 27 & 12 & 192 & 31 & 12 \\
\hline Metronidazole-OH & MOR-d3 & + & 188.02 & 26 & 123.1 & 19 & 12 & 125.9 & 23 & 6 \\
\hline PAR-d4 & - & + & 156.2 & 26 & 139.2 & 9 & 8 & 114.1 & 23 & 6 \\
\hline GAB-d10 & - & + & 182.14 & 46 & 164.1 & 17 & 10 & 147.1 & 23 & 8 \\
\hline SMX-d4 & - & + & 258.09 & 56 & 160 & 21 & 8 & 112 & 33 & 4 \\
\hline MOR-d3 & - & + & 289.17 & 71 & 155.2 & 77 & 8 & 131.2 & 75 & 8 \\
\hline Ibuprofen (IBU) & IBU-d3 & - & 204.98 & -30 & 161 & -10 & -1 & 158.9 & -10 & -9 \\
\hline Piperacillin & IBU-d3 & - & 516.17 & -50 & 232.9 & -24 & -13 & 329.9 & -16 & -5 \\
\hline Diclofenac & IBU-d3 & - & 296.02 & -35 & 251.9 & -16 & -17 & - & - & - \\
\hline Mefenamic acid-OH & IBU-d3 & - & 255.96 & -60 & 181.9 & -28 & -9 & - & - & - \\
\hline Ibuprofene-d3 & - & - & 207.98 & -30 & 164 & -10 & -1 & 161.9 & -10 & -9 \\
\hline
\end{tabular}

Table 2. Instrument calibration range, instrument detection (IDL) and quantification (IQL) limits, and method detection (MDL) and quantification (MQL) limits.

\begin{tabular}{|c|c|c|c|c|c|c|c|}
\hline Compound & $\begin{array}{l}\text { Regression } \\
\text { coefficient }\end{array}$ & $\begin{array}{l}\text { Instrument Calibration } \\
\text { Range }[\mu \mathrm{g} / \mathrm{L}]\end{array}$ & $\begin{array}{l}\text { Method Calibration } \\
\text { Range }[\mu \mathrm{g} / \mathrm{L}]\end{array}$ & $\begin{array}{l}\text { IDL } \\
{[\mu \mathrm{g} / \mathrm{L}]}\end{array}$ & $\begin{array}{l}\mathrm{IQL} \\
{[\mu \mathrm{g} / \mathrm{L}]}\end{array}$ & $\begin{array}{l}\text { MDL } \\
{[\mathrm{ng} / \mathrm{L}]}\end{array}$ & $\begin{array}{l}\text { MQL } \\
{[\mathrm{ng} / \mathrm{L}]}\end{array}$ \\
\hline Metronidazole & 0.999 & $5-250$ & $0.1-1000$ & 0.1 & 0.25 & 2 & 100 \\
\hline Paracetamol & 0.997 & $10-500$ & $0.2-2500$ & 1 & 1.5 & 20 & 200 \\
\hline Gabapentin & 0.998 & $5-250$ & $0.1-1000$ & 0.1 & 0.25 & 2 & 100 \\
\hline Codeine & 0.997 & $5-250$ & $0.1-1000$ & 0.5 & 1.25 & 10 & 200 \\
\hline Morphine & 0.998 & $10-500$ & $0.2-2500$ & 1.25 & 3 & 25 & 200 \\
\hline Sulfamethoxazole & 0.999 & $5-250$ & $0.1-1000$ & 0.5 & 1.2 & 10 & 100 \\
\hline Carbamazepine & 0.994 & $2.5-125$ & $0.05-500$ & 0.005 & 0.1 & 0.1 & 50 \\
\hline Metronidazole-OH & 0.997 & $10-500$ & $0.2-2500$ & 0.05 & 1 & 1 & 200 \\
\hline Ciprofloxacin & 0.998 & $10-500$ & $0.2-2500$ & 1.5 & 3 & 30 & 200 \\
\hline Ibuprofen & 0.999 & $10-500$ & $0.2-2500$ & 5 & 10 & 100 & 200 \\
\hline Piperacillin & 0.996 & $5-250$ & $0.1-1000$ & 0.1 & 0.5 & 2 & 100 \\
\hline Diclofenac & 0.999 & $2.5-125$ & $0.05-500$ & 0.1 & 1 & 2 & 50 \\
\hline Mefenamic acid-OH & 0.999 & $5-250$ & $0.1-1000$ & 0.05 & 0.2 & 1 & 100 \\
\hline
\end{tabular}


0.05 to $2500 \mu \mathrm{g} / \mathrm{L}$. This doubles the time of analysis but allows the quantification of active ingredients, which are expected to be found at very low concentrations (e.g. diclofenac), as well as very high ones (e.g. paracetamol).

The instrument detection limits (IDL) vary from 0.05 to $5 \mu \mathrm{g} / \mathrm{L}$ depending on the compound (Table 2). Therefore, with a concentration factor of 50 the method detection could reach the ng/L level, but the quantification limits were set at the first standard level (0.05-0.2 $\mu \mathrm{g} / \mathrm{L})$ according to the expected levels in effluent samples.

Precision of the method in ultrapure water, evaluated with Quality Controls (QC) at four different concentrations, analyzed in triplicate during three different days, was satisfactory. Trueness of all QC was comprised between 80 and $120 \%$, except for carbamazepine which shows a trueness of 71.6 and $123 \%$ for the first and third QC respectively. Intra-day $(\mathrm{CVr})$ and inter-day (CVR) variability were below 20 and $30 \%$ respectively.

Dilution integrity was evaluated with 2 QC at 100 and $1000 \mu \mathrm{g} / \mathrm{L}$ analyzed in triplicate and for three different days. Trueness of the diluted samples varied between 75.1 and $99.8 \%$, except for gabapentin $(69.2 \%)$ and carbamazepine $(55.9 \%)$ for which the diluted QC $(200 \mu \mathrm{g} / \mathrm{L})$ was above their upper limit of quantification (ULOQ = $125 \mu \mathrm{g} / \mathrm{L})$. Furthermore, these compounds are not expected to be found in high concentrations in the hospital effluents. Coefficients of variation were all below $20 \%$.

\subsection{Quantitative Analysis of Hospital Effluent Samples}

Mean recoveries of API in hospital wastewater samples spiked at $100 \mu \mathrm{g} / \mathrm{L}$ varied between 76 and $111 \%$, with relative standard deviation (RSD) between 1.1 and $10.7 \%$ (Fig. 3). At lower concentrations $(0.1,1$ and $10 \mu \mathrm{g} / \mathrm{L})$ mean recoveries varied between 66.8 and $132.9 \%$ and RSD between 0.6 and $28.5 \%$, with the exception of piperacillin $(46.4-49.6 \pm 3.6-4 \%)$, as well as mefenamic acid-OH at $10 \mu \mathrm{g} / \mathrm{L}$ $(43.9 \pm 4.1 \%)$ and ciprofloxacin at $0.1 \mu \mathrm{g} / \mathrm{L}$ $(44.4 \pm 32.9 \%)$. The higher RSD observed at the lowest concentration $(0.1 \mu \mathrm{g} / \mathrm{L})$ can be explained by the elevated concentrations found in the blank samples, especially for ibuprofen, $(3.2 \mu \mathrm{g} / \mathrm{L})$, gabapentin (1.5 $\mu \mathrm{g} / \mathrm{L})$, mefenamic acid-OH $(1.3 \mu \mathrm{g} / \mathrm{L})$, paracetamol $(0.3 \mu \mathrm{g} / \mathrm{L})$ and ciprofloxacin $(0.1 \mu \mathrm{g} / \mathrm{L})$. Indeed, in environmental research blank matrices are rarely available and the standard addition method, or the matrix-match calibration are not suitable for wastewater analysis.[21] Internal calibration has been found to be reliable in order to compensate the matrix effect, as long as the labeled standard elutes close to the standard itself. Thus, the observed uncertainties can also be due to the difference in signal suppression between analytes and their related internal standards (Fig. 4). Indeed, diluted samples showed lower signal suppression than concentrated ones, especially for internal standards, and some compounds showed less difference, which can explain their over- or under-estimation in analyzed spiked samples. In any case, the chosen IS were shown to allow the correct quantification of all compounds. In order to avoid a too strong matrix effect, and, by this way, to insure falling into the calibration range, dilution of samples is often performed. ${ }^{[13,22,23]}$ In our case, the samples were analyzed twice (concentrated and diluted) according to the procedures described above (section 2.3), and a preliminary dilution step was added along with the sample acidification before the SPE.

The method developed above was applied to the study of the contamination of effluents in the main building of one of the largest university hospitals in Switzerland. The majority of the studied API exhibited a detection frequency of $100 \%$, with the exception of diclofenac (79\%), and piperacillin (54\%). This confirms the usefulness of our previous selection work based on the hospital pharmacy data. ${ }^{[17]}$ A possible explanation of the low detection frequency of the antibiotic piperacillin would be a fast degradation in wastewaters. Concentrations ranged from 0.1 to $1535 \mu \mathrm{g} / \mathrm{L}$, and daily loads from 0.07 to $290 \mathrm{~g} / \mathrm{d}$ depending on the compound (Table 3). Some API were detected at low concentrations (codeine, gabapentin, carbamazepine, mefenamic acid-OH), and others were found at high concentrations (morphine, sulfamethoxazole, ciprofloxacin, ibuprofen, metronidazole, metronidazole-OH) and very high concentrations (paracetamol). In general, concentration ranges and mean values of API were in the same order of magnitude as previous results from other hospitals. ${ }^{[6,13]}$ Some differences in concentration ranges were observed between the June and the July samples, especially for the analgesic paracetamol, the antibiotics metronidazole and sulfamethoxazole and the psycho-active drug gabapentin. A possible explanation would be the holiday period for many collaborators, as well as fewer outpatient consultations during the July period.

\section{Conclusions}

The developed analytical method for the simultaneous quantification of 13 active pharmaceutical ingredients in hospital effluents has been successfully validated. The method showed acceptable precision and selectivity. The matrix effect has been discussed and its correction by internal standards was satisfactory. This method
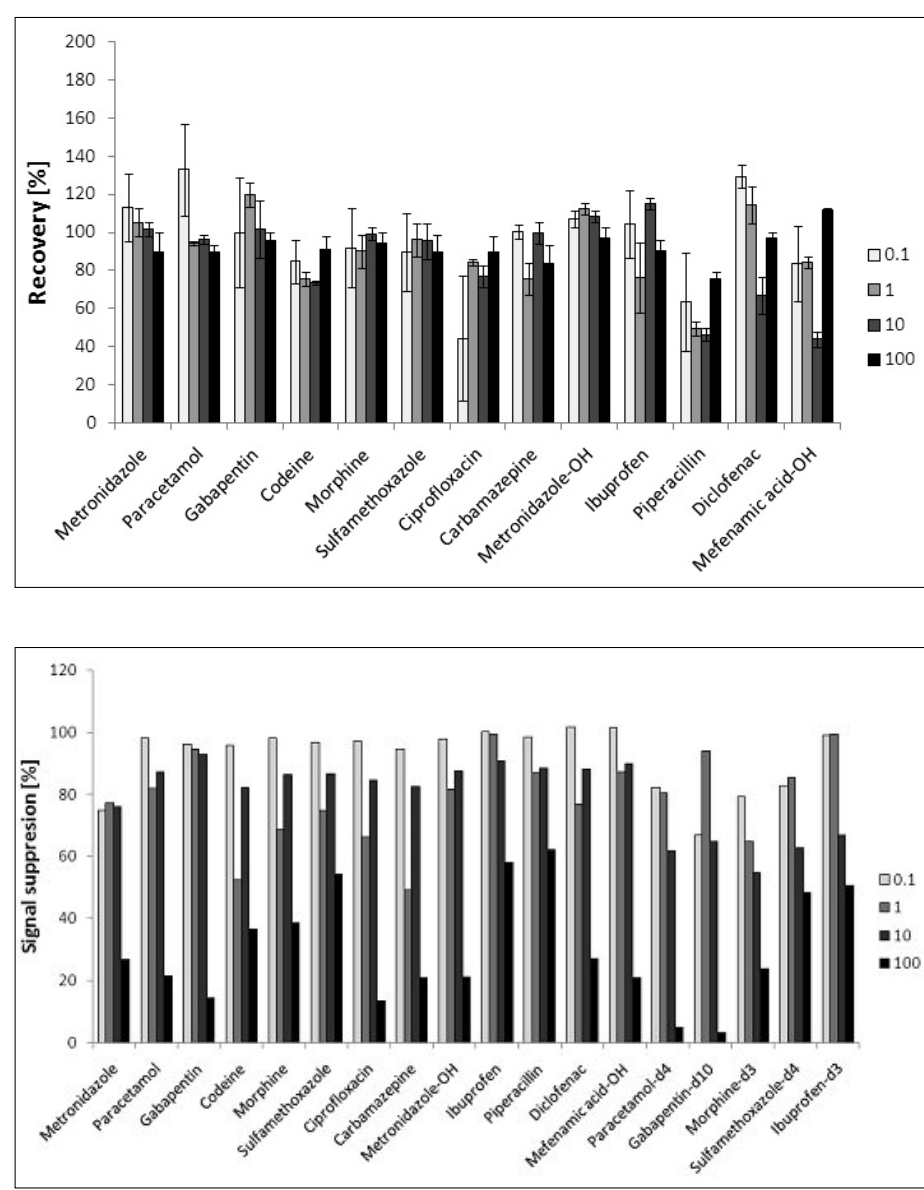

Fig. 3. Mean recoveries of spiked hospital wastewater samples at four different concentrations $(0.1$, $1,10$ and $100 \mu \mathrm{g} / \mathrm{L})$.

Fig. 4. Signal suppression in spiked hospital wastewater samples at four different concentrations $(0.1,1,10$ and 100 $\mu \mathrm{g} / \mathrm{L}$ ) as compared to their equivalent concentrations in solvent $(0.1 \%$ formic acid-acetonitrile $80: 20, v / v)$. 
Table 3. Range of API residue concentrations and loads observed in the sewer of the main building of a Swiss university hospital during two different weeks in June and July 2014 ( $\mathrm{n}=24$ samples). MLQ = Method Limit of Quantification.

\begin{tabular}{|l|l|l|l|l|}
\hline Compound & $\begin{array}{l}\text { Concentration } \\
\text { range }[\mu \mathrm{g} / \mathrm{L}]\end{array}$ & $\begin{array}{l}\text { Mean concen- } \\
\text { tration }[\mu \mathrm{g} / \mathrm{L}]\end{array}$ & $\begin{array}{l}\text { Daily load } \\
\text { range }[\mathrm{g} / \mathrm{d}]\end{array}$ & $\begin{array}{l}\text { Mean daily } \\
\text { load [g/d] }\end{array}$ \\
\hline Metronidazole & $1.1-45.3$ & 13.6 & $0.35-9.9$ & 2.91 \\
\hline Paracetamol & $304-1535$ & 655.9 & $66-290$ & 141.95 \\
\hline Gabapentin & $0.6-20.8$ & 5.9 & $0.11-6.12$ & 1.59 \\
\hline Codeine & $0.4-4.0$ & 1.9 & $0.12-0.77$ & 0.40 \\
\hline Morphine & $37-103.2$ & 66.8 & $8.05-30.26$ & 14.79 \\
\hline Sulfamethoxazole & $6.5-101.6$ & 44.3 & $2.04-30.85$ & 9.15 \\
\hline Ciprofloxacin & $33.7-292$ & 93.7 & $3-59$ & 18.1 \\
\hline Carbamazepine & $0.3-11.7$ & 3.6 & $0.1-1.97$ & 0.71 \\
\hline Metronidazole-OH & $3.4-57.2$ & 21.8 & $0.65-17.37$ & 4.88 \\
\hline Ibuprofen & $19.4-204$ & 76.7 & $6.9-46.0$ & 16.76 \\
\hline Piperacillin & $<$ MLQ & $<$ MLQ & $<$ MLQ-0.07 & 0.02 \\
\hline $\begin{array}{l}\text { Diclofenac } \\
\text { Mefenamic acid-OH }\end{array}$ & $<$ MLQ & $<$ MLQ & $<$ MLQ-0.11 & 0.04 \\
\hline & & 2.1 & $0.03-1.92$ & 0.47 \\
\hline
\end{tabular}

was applied to wastewater samples from the main building of a Swiss university hospital and allowed the proper quantification of the targeted compounds. Concentrations vary from 0.1 to $1535 \mu \mathrm{g} / \mathrm{L}$ according to the compound. This analytical development allows the implementation of monitoring campaigns and a better comprehension of hospital pharmaceutical residues dynamics in urban wastewaters.

\section{Acknowledgements}

We would like to thank Profs P. Dayer and A. Perrier from the HUG Medical Direction, as well as A. Samson from the HUG Environmental Management for their support to this project.
[7] K. Helwig, C. Hunter, J. MacLachlan, M. McNaughtan, J. Roberts, A. Cornelissen, C. Dagot, H. Evenblij, K. Klepiszewski, S. Lyko, I. Nafo, C. McArdell, S. Venditti, O. Pahl, J. Environ. Anal. Toxicol. 2013, 3, 177.

[8] K. S. Le Corre, C. Ort, D. Kateley, B. Allen, B. I. Escher, J. Keller, Environ. Int. 2012, 45, 99.

[9] P. Verlicchi, M. Al Aukidy, E. Zambello, Sci. Total Environ. 2012, 429, 109.

[10] K. Fent, A. A. Weston, D. Caminada, Aquat. Toxicol. 2006, 76, 122.

[11] M. Gros, S. Rodríguez-Mozaz, D. Barceló, J. Chromatogr. A 2012, 1248, 104.

[12] R. López-Serna, M. Petrović, D. Barceló, Chemosphere 2011, 85, 1390.

[13] M. J. Gómez, M. Petrović, A. R. FernándezAlba, D. Barceló, J. Chromatogr. A 2006, 1114, 224.

[14] S. Castiglioni, R. Bagnati, D. Calamari, R. Fanelli, E. Zuccato, J. Chromatogr. A 2005, 1092, 206.

[15] M. Gros, S. Rodriguez-Mozaz, D. Barcelo, $J$. Chromatogr. A 2013, 1292, 173.

[16] N. Negreira, N. Mastroianni, M. López de Alda, D. Barceló, Talanta 2013, 116, 290.

[17] S. Daouk, N. Chèvre, N. Vernaz, P. Bonnabry, P. Dayer, Y. Daali, S. Fleury-Souverain, J. Environ. Manage. 2015, 160.

[18] D. Ortelli, P. Edder, F. Rapin, S. Ramseier, Rapp. Comm. Int. Prot. Eaux Léman contre Pollut. 2011, 65.

[19] C. E. Kindsvater, R. W. Carter, Trans. Am. Soc. Civ. Eng. 1959, 24, 772.

[20] US EPA, 'Load estimation techniques. National Management Measures to Control Nonpoint Source Pollution from Agriculture', Washington, DC, 2003, 225.

[21] J. Nurmi, J. Pellinen, J. Chromatogr. A 2011, $1218,6712$.

[22] B. Morasch, F. Bonvin, H. Reiser, D. Grandjean, L.F. de Alencastro, C. Perazzolo, N. Chevre, T. Kohn, Environ. Toxicol. Chem. 2010, 29, 1658.

[23] C. Ort, M. G. Lawrence, J. Reungoat, G. Eaglesham, S. Carter, J. Keller, Water Res. 2010, 44,605 . 